\title{
Anesthesia and maternal hypertensive disorders - analysis of a tertiary maternity center
}

\author{
Rêgo S., Lima M., Silva C., Alves C., Carvalhas J.
}

Coimbra Hospital and University Centre, Dept of Anaesthesiology, Coimbra, Portugal

Hypertension is the most common medical problem complicating 2-3\% of pregnancies (I). Maternal hypertensive disorders and their implications, are a growing reality faced by the obstetric anesthetist.

The aim of this study is to characterize the obstetric patients with hypertensive disorders admitted in a tertiary maternity from June 2015 to June 2016, and analyse their anesthetic/analgesic management.

A retrospective analysis was carried out by reviewing clinical data of consecutive patients diagnosed with chronic hypertension, gestational hypertension, preeclampsia, and severe preeclampsia and HELLP syndrome, in our maternity in the considered time frame.

A descriptive analysis was performed. Continuous variables were reported as mean (standard deviation).

$\checkmark$ In this period there were 2670 deliveries and the incidence of hypertensive pathology was 3,9\% $(n=104)$, which is in agreement with the literature.

$\checkmark$ The average age was $34 \pm 4,7$ years, $44 \%$ were nulliparous and $6,7 \%$ had multiple pregnancies.

Sixty one percent were obese.

Severe preeclampsia/ HELLP syndrome $8,70 \%$

Gestacional hypertension $29,80 \%$

Chronic hypertension $29,80 \%$

Preeclampsia

$31,70 \%$

$0,00 \% 5,00 \% 10,00 \% 5,00 \% 0,00 \% 5,00 \% 0,00 \% 5,00 \%$

Graphic 1 - Maternal hypertensive disorders (\%)

$\checkmark$ The overall incidence of preterm deliveries was $41 \%(n=43)$, and in 17 of these $(39,5 \%)$, the gestational age was under 34 weeks.

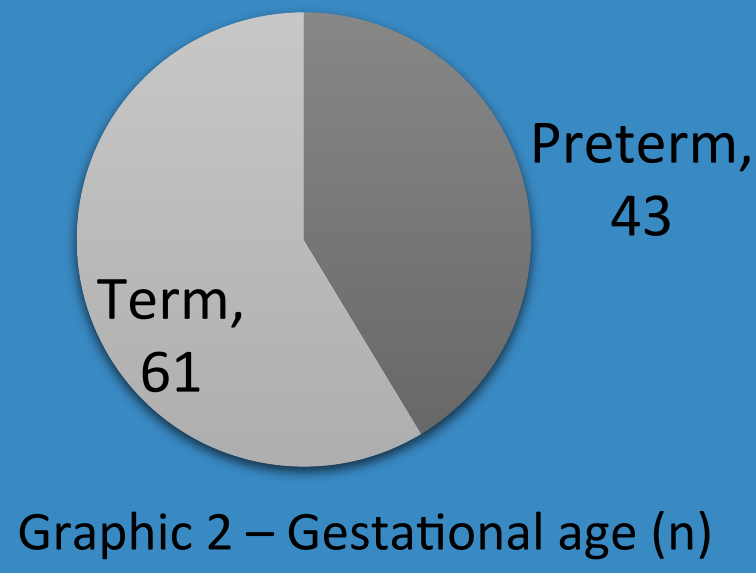

\begin{tabular}{l|c|c|c|} 
& $\begin{array}{c}\text { Vaginal } \\
(\mathrm{n})\end{array}$ & $\begin{array}{c}\text { C-section } \\
(\mathrm{n})\end{array}$ & $\begin{array}{c}\text { Total } \\
(\mathrm{n})\end{array}$ \\
\hline $\begin{array}{l}\text { Chronic hypertension } \\
\text { Gestational hypertension }\end{array}$ & 16 & 15 & 31 \\
\hline $\begin{array}{l}\text { Preeclampsia } \\
\text { Severe preeclampsia/ }\end{array}$ & 14 & 14 & 31 \\
\hline HELLP syndrome & 1 & 8 & 33 \\
\hline Total & 48 & 56 & 104
\end{tabular}

Graphic 3 - Type of delivery of maternal hypertensive disorders (n)

$\checkmark$ The percentage of neuroaxial techniques for labor analgesia was very high (94\%).

The caesarean section rate in the hypertensive pathology group was $53,8 \% \quad(n=56)$. Severe preeclampsia and HELLP syndrome had the highest rate, $80 \%$ and $100 \%$ respectively.

General anesthesia was performed in $27,3 \%(n=15)$ caesarean sections.

Maternal hypertensive disorders demand an interdisciplinary approach with an early involvement of the anesthetic team.

We found a very high c-section rate in the studied group contrasting with the overall c-section rate $(29,3 \%)$ of the maternity. Similarly, there was a high general anesthesia rate.

The high neuroaxial analgesia percentage can be explained by the fact that, in our institution, epidural catheters are placed very early during labor. 